\title{
Neural responses to affective pictures while anticipating and perceiving respiratory threat
}

\author{
Georgiana Juravle ${ }^{1,2}$, Phillipp Reicherts ${ }^{3}$, Mirjam Riechmann-Weinstein ${ }^{1}$, \\ Matthias J. Wieser ${ }^{3,4}$, \& Andreas von Leupoldt ${ }^{1,5}$ \\ ${ }^{1}$ Department of Systems Neuroscience, University Medical Center Hamburg-Eppendorf \\ Hamburg, Germany \\ ${ }^{2}$ ImpAct Team, French National Institute of Health and Medical Research, INSERM U1028 \\ Lyon, France \\ ${ }^{3}$ Department of Psychology, University of Würzburg \\ Würzburg, Germany \\ ${ }^{4}$ Institute of Psychology, Erasmus University Rotterdam \\ Rotterdam, Netherlands \\ ${ }^{5}$ Research Group Health Psychology, University of Leuven \\ Leuven, Belgium
}

\author{
ADDRESS FOR CORRESPONDENCE: \\ Dr. Georgiana Juravle \\ ImpAct Team, French National Institute of Health and Medical Research, INSERM U1028 \\ Lyon Neuroscience Research Center \\ 16 avenue Doyen Lépine \\ 69676 Bron, France \\ E-mail: georgiana.juravle@inserm.fr \\ TEL: +33 (0)4 729134 18; FAX: +33 (0)4 72913401 .
}




\title{
ANTICIPATING AND PERCEIVING BREATHLESSNESS
}

\begin{abstract}
Emotional processes have an impact on the anticipation and perception of bodily threat sensations, such as breathlessness. However, little is known about the reverse influence of breathlessness on emotional processes, as well as its modulation by anxiety sensitivity (AS). Here we investigated by means of visually-evoked potentials how the perception vs. anticipation of resistive-load-induced breathlessness (RLIB) influences emotional processing. High (HA) and low anxious (LA) participants viewed pictures of positive, neutral, or negative content under conditions of perceived RLIB, anticipated RLIB, or else, an unloaded baseline. The P2 (230-290 ms) was significantly less positive under perceived RLIB. Furthermore, the early LPP (300-500 ms) was significantly less positive during both RLIB conditions, as compared to baseline. Overall, the P1 was significantly more positive in HA as compared to LA individuals. Additionally, across conditions the late LPP (600-1000 ms) was enhanced for positive and negative pictures as opposed to neutral ones for the LA group. In contrast, for the HA group only the positive pictures elicited the typical enhanced LPP. Notably, for the HA participants negative pictures elicited significantly blunted late LPPs during perceived RLIB as compared to anticipated RLIB and baseline. A reversed effect (i.e., more positivity) for was observed for LA participants, suggesting motivational priming. Taken together, these results highlight the impact of perceived and anticipated respiratory threat on the neural processing of emotional picture stimuli, as well as its modulation by anxiety sensitivity levels.
\end{abstract}

Keywords: Affective processing; respiratory threat; resistive load; breathlessness; anxiety sensitivity. 


\section{ANTICIPATING AND PERCEIVING BREATHLESSNESS}

\section{INTRODUCTION}

The understanding of a severe bodily threat sensation, such as breathlessness, is crucial for somatic and psychological disorders (Barlow, 2002; Domschke, Stevens, Pfleiderer, \& Gerlach, 2010; Hamm, Richter, \& Pané-Farré, 2014). Moreover, the perception of bodily threat sensations is closely linked to emotional experience (James, 1894; Schachter \& Singer, 1962). Researchers have so far approached breathlessness by investigating how affective states influence its perception. For example, it has been convincingly demonstrated that affective states significantly alter the perception of breathlessness, a prominent effect evident both at a behavioural as well as at a neural level (Janssens, Verleden, De Peuter, Van Diest, \& Van den Bergh, 2009; von Leupoldt, Chan, Esser, \& Davenport, 2013; von Leupoldt, Mertz, Kegat, Burmester, \& Dahme, 2006). However, the reverse path of how breathlessness itself affects the processing of emotional stimuli has not received as much attention.

Recently, we utilized Event-related potentials (ERPs) in order to investigate the effect that breathlessness exerts on emotional processing (Juravle et al., 2014). Our participants viewed either positive, neutral, or negative pictures under conditions of resistive-load-induced breathlessness (RLIB). Results indicated that the ERPs locked to picture onset were significantly affected by the bodily threat stimulus. Specifically, breathlessness reduced the early deflections of the ERP within up to $300 \mathrm{~ms}$ post-stimulus onset, thus suggesting that it is the early neural processing of visual picture stimuli that is affected during breathlessness, result indicating a strong attentional capture of breathlessness. Similarly, a reduced P1, but also late positive potential (LPP) for emotional pictures were demonstrated during perceived pain conditions (Wieser, Gerdes, Greiner, Reicherts, \& Pauli, 2012). 


\section{ANTICIPATING AND PERCEIVING BREATHLESSNESS}

Moreover, it has been suggested that the anticipation of breathlessness might be more important than its perception in respiratory and psychological disorders as it motivates (often maladaptive) avoidance behaviour (Hayen, Herigstad, \& Pattinson, 2013; Paulus, 2013). For example, the repeated aversive experience of breathlessness in patients with chronic obstructive pulmonary disease (COPD) can lead to fear of breathlessness. The subsequent fearful anticipation of breathlessness is believed to lead to avoidance of contexts that are associated with breathlessness (e.g., physical activity), thus fuelling a downward spiral of physical deconditioning, increased breathlessness, increased anticipatory fear, and progressive reductions in health status and the quality of life (Troosters et al., 2013; von Leupoldt \& Janssens, 2016). In this regard, several studies concerned with the anticipation of breathlessness have highlighted significant physiological fear responses, including activations of fear-related brain areas such as insula, anterior cingulate cortex, and amygdala (Holtz, Pané-Farré, Wendt, Lotze, \& Hamm, 2012; Melzig, Michalowski, Holtz, \& Hamm, 2008; Pappens, Smets, Vansteenwegen, Van Den Bergh, \& Van Diest, 2012; Paulus et al., 2012; Stoeckel, Esser, Gamer, Kalisch, et al., 2015; Stoeckel, Esser, Gamer, Büchel, \& von Leupoldt, 2015).

In light of these results, we were interested to investigate whether not only the perception of breathlessness, but also the mere anticipation of such a severe bodily threat would result in a similar modulation of the neural processing of affective picture stimuli. Recent research has highlighted altered startle responses (Nelson, Hajcak, \& Shankman, 2015), as well as modulations of the early electrophysiological responses during the anticipation of aversive events such as threat of shock (Nelson, Hajcak, \& Shankman, 2015; Seidel et al., 2015), or public speaking (Wieser, Pauli, Reicherts, \& Mühlberger, 2010), as well as during the experience of a smell-based threat context (Kastner, Flohr, Pauli, \& Wieser, 2015). For example, it has been demonstrated that the later ERPs 


\section{ANTICIPATING AND PERCEIVING BREATHLESSNESS}

(e.g., P3 or the LPP) are reduced during the anticipation of threat (Nelson, Hajcak, et al., 2015), as well as during perception of pain (Wieser et al., 2012).

In addition, breathlessness seems to be affected by trait anxiety levels, in that high anxious individuals demonstrate an increased perception of breathlessness, whereas low anxious individuals exhibit a decrease in the perception of breathlessness (Livermore et al., 2012; Stoeckel, Esser, Gamer, Büchel, et al., 2015). Especially high levels of anxiety sensitivity - a dimensional trait measure of the belief that physiological symptoms might signal severe bodily circumstances - seem to be related to specific bodily threat such as breathlessness (Alius, Pané-Farré, Von Leupoldt, \& Hamm, 2013; Melzig et al., 2008). Moreover, the modulation of neural responses during the anticipation of threat has been shown to correlate with increased trait levels of (anxious) cognitive, as well as physical, concerns (Nelson, Hodges, et al., 2015).

In the present study, our participants viewed pictures of emotional content under conditions of perceived RLIB, anticipated RLIB, as well as an unloaded baseline, while the continuous EEG was recorded. We were particularly interested in the early modulations of the picture locked ERPs we have previously observed, as well as the more common, later affect-related ERPs. The hypothesis predicted reduced ERPs for both RLIB conditions relative to the baseline, together with significantly enhanced ERPs to emotional relative to neutral picture viewing. In addition, we predicted modulations of the ERPs of interest as a function of anxiety sensitivity, during both perceived and anticipated breathlessness.

\section{METHOD}

\section{Participants}

Forty individuals participated in the experiment. They were recruited from the local institute 


\section{ANTICIPATING AND PERCEIVING BREATHLESSNESS}

database and they were students in their majority. Out of these, the data from four participants had to be removed because of amplifier failure severely affecting the EEG. Furthermore, during data analysis another two participants needed to be excluded from the final sample, see Methods below for particulars. The remaining sample consisted of 34 participants (18 males) with an average age of 27 years (age range: 21-39 years). All participants reported normal respiratory status, as well as normal or corrected to normal vision. Baseline lung function was assessed by spirometry in accordance with the European Respiratory Society standards (Miller et al., 2005). The dispositional (trait) level of anxiety sensitivity in all participants was measured with the validated German version of the anxiety sensitivity index 3 (the ASI3 questionnaire, Kemper, Ziegler, \& Taylor, 2009; Taylor \& Cox, 1998; Taylor et al., 2007). The questionnaire was computer-administrated and the mean ASI score was 19.12 ( $\mathrm{SD}=9.74$, general scores range: $5-41)$. No significant difference was observed when comparing the ASI scores between male and female participants in both the low anxious group $(t(15)=1.39, p=.184, r=.34)$, as well as the high anxious group of our sample $(t(15)=.098, p=.923, r=.03)$. See Table 1 for a summary of the demographic data. Participants received monetary remuneration for their participation. The study protocol was approved by the ethics committee of the Medical Association Hamburg and written informed consent was obtained from all participants before the beginning of the experiment.

\section{Resistive load breathing}

Resistive-load-induced breathlessness (RLIB) was induced by breathing through inspiratory resistive loads, a procedure known to increase the work of the respiratory muscles (Harver \& Mahler, 1998). Participants wore a nose clip and breathed via a mouthpiece attached to a breathing circuit including an antibacterial filter, a pneumotachograph, and a non-rebreathing valve, all connected in series. The inspiratory port of the valve was connected to a tube facilitating the easy 


\section{ANTICIPATING AND PERCEIVING BREATHLESSNESS}

introduction and removal of the inspiratory resistive loads, while the expiratory port was left free.

The magnitude of the load was estimated during a pre-test phase. The aim of the pre-test was to derive, for each participant, a breathlessness threshold corresponding to a sensation of strong breathlessness, matched to a score for breathlessness intensity of $>/=5$ on a 0-10 Borg scale (Borg, 1982). Additionally, a load inducing a very strong sensation of breathlessness (Borg score of 9 or 10) was also determined. A breathlessness thresholding procedure consisting of maximum 20 trials was developed and administered. Participants were seated comfortably and instructed to fixate on a screen and breathe normally through the breathing system. One pre-test trial consisted of 24 seconds of loaded breathing, followed by the presentation of the Borg scale and the requirement to rate the breathlessness intensity. We utilized a set of 10 loads with their intensity derived based on previous experiments in our lab. Note that since these loads values were based on subjective ratings of intensity or unpleasantness of breathlessness, the physical difference from one load to another was not constant. A full list of the loads values utilized is provided in Footnote 1. The staircase always started with the same value of the load for all the participants (test value $=.76 \mathrm{kPa} / \mathrm{l} / \mathrm{s}$ ).

If the current rating for the trial was $</=5$ and the current strength of the load was smaller or equal to the test value, the staircase always increased the strength of the load with a step. The staircase instead kept the previous load for those cases when either the current rating was $</=5$ and the load was stronger than the test value, or for those cases when the rating was larger than 5, but the given load was smaller or equal to the test value. If the ratings were higher than 5 , the staircase always decreased the load strength by one step when the intensity of the load was stronger than the test value. See Figure 1 for a depiction of the staircase procedure. The first four trials of the pre-test were not considered for the calculation of the final threshold. The staircase procedure stopped as soon as 3 trials with ratings higher than 6 were recorded. The threshold was recorded as the last 


\section{ANTICIPATING AND PERCEIVING BREATHLESSNESS}

value of the staircase. The resulting average resistance of the load for the current sample of participants was $1.18 \mathrm{kPa} / 1 / \mathrm{s}$.

\section{Emotional Picture Series}

A set of 180 pictures was chosen from the International Affective Picture System (IAPS), based on normative mean arousal and valence ratings (Lang et al., 2008); see Footnote 2 for statistics particulars and Footnote 3 for the exact picture codes utilized in the study. The emotional pictures were grouped into positive (e.g., erotica, individuals laughing), neutral (e.g., objects, neutral sceneries), and negative (e.g., mutilations, threatening scenes) categories, each comprising 60 pictures. For each emotional category, 3 picture series of 20 pictures each were created, carefully matched with regard to their normative ratings of valence/arousal and their physical content, both within each block, as well as across blocks.

\section{Subjective ratings}

Participants rated the experienced intensity and unpleasantness of breathlessness, as well as fear after each experimental block. These subjective ratings were collected on a computer-based horizontal visual analogue scale (VAS) ranging from 0 (not noticeable/unpleasant/fearful) to 100 (maximally imaginable intensity/unpleasantness/fearful), which is an established and commonly used measure of breathlessness in experimental studies (Dyspnea, 1999; Meek, Lareau, \& Hu, 2003; von Leupoldt et al., 2008).

\section{EEG recording and preprocessing}

The EEG was recorded continuously from $60 \mathrm{Ag} / \mathrm{AgCl}$ scalp electrodes mounted on a 


\section{ANTICIPATING AND PERCEIVING BREATHLESSNESS}

custom elastic cap with 64 electrode positions (active electrodes; ActiCAP, Brain Products GmbH, Gilching, Germany). The signal was referenced on-line to the $\mathrm{FCz}$ electrode and re-referenced offline to an average of the entire electrodes set; the recording reference was re-utilized for further analyses. The electrode impedances were kept below $20 \mathrm{k} \Omega$. Vertical eye movements were measured with two additional electrodes placed beneath and above the left eye, using the same reference as for the other electrodes. Horizontal eye movements were calculated offline by subtracting the signal recorded at two additional electrodes positioned outside the cap near the outer canthi of the eyes (i.e., electrodes F9 and F10 in the 10-10 electrode system, Oostenveld and Praamstra, 2001).

The electrode signals were amplified using two BrainAmp amplifiers with 32 channels each (Brain Products $\mathrm{GmbH}$ ) and digitally stored using the BrainVision Recorder software (Brain Products $\mathrm{GmbH}$ ). The analogue EEG signal was sampled at $500 \mathrm{~Hz}$ and filtered on-line with a high cut-off at $1000 \mathrm{~Hz}$. The signal was then filtered offline with a high cut-off at $30 \mathrm{~Hz}, 24 \mathrm{~dB} / \mathrm{oct}$.

As a first step in the ERP analysis, the EEG data preprocessing was conducted with VisionAnalyzer 2 (Brain Products GmbH). The EEG signal was initially segmented into bins of $200 \mathrm{~ms}$ pre-, and 1000 ms post-visual-stimulus delivery. The vertical electrooculogram segmented data were submitted to a blink artefact rejection (segments with an absolute voltage difference between maximum and minimum sample points higher than $60 \mu \mathrm{V}$ were removed). For the remaining 60 scalp electrodes, segments with an absolute voltage difference between maximum and minimum sample points higher than $100 \mu \mathrm{V}$, as well as segments with low activity $(<.5 \mu \mathrm{V})$ for a period of more than $100 \mathrm{~ms}$ were removed, to reject other movement and amplifier artefacts. The remaining artefact-free data were then averaged by condition and baseline corrected (200 ms pre-stimulus baseline). The averages for each block for each participant were exported to Matlab (Matlab 2009b, 


\section{ANTICIPATING AND PERCEIVING BREATHLESSNESS}

MathWorks, Natick, MA, USA) for the remaining analysis. Topographic maps were derived in EEGLAB (Delorme \& Makeig, 2004).

After visual inspection of our data, and in accordance with previous ERP literature on emotional picture processing (Hajcak, MacNamara, \& Olvet, 2010; Olofsson, Nordin, Sequeira, \& Polich, 2009), we focused the analysis on three deflections commonly related to emotional picture processing. The first considered positive deflection was the $P l$ analysed at the posterior occipital electrode POz in the early latency range of $120-140 \mathrm{~ms}$ post-stimulus onset. $P 1$ is associated with early sensory stimulus processing and selective attention (see Olofsson et al., 2009, for a review). The next ERP deflection taken into account was the $P 2$ analysed at $\mathrm{Pz}$ in the middle latency range of 230 - $290 \mathrm{~ms}$ post-stimulus onset, an ERP commonly related to modality-specific selective attention (e.g., Crowley \& Colrain, 2004). Finally, the slow positive deflection (the LPP) usually found $300 \mathrm{~ms}$ post-stimulus onset over centro-parietal sites was analyzed in an early time window between $300-500 \mathrm{~ms}$ latency range (at $\mathrm{CPz}$ and $\mathrm{Pz}$ ), as well as in a later time window between 600 and $1000 \mathrm{~ms}$, at central posterior sites $(\mathrm{Cz}, \mathrm{CPz}$, and $\mathrm{Pz})$. The $L P P$ has been described as an index of sustained emotional processing and motivated attention (Cuthbert et al., 2000). All investigated ERPs in the current study were calculated as averaged activity over the particular time window of interest, at the specified groups of electrodes.

\section{Procedure}

After standardized instructions and spirometric lung function measurements, the participants underwent the pre-test for the selection of the individual resistive loads. Thereafter, the EEG cap and nose clip were attached. The participants were seated in a comfortable chair at $110 \mathrm{~cm}$ viewing distance from the monitor (Samsung SyncMaster P2370, refresh rate of $60 \mathrm{~Hz}$ ). The experiment was 


\section{ANTICIPATING AND PERCEIVING BREATHLESSNESS}

conducted on a Windows XP computer with a GeForce 6600 graphics card (PCIe/S8E 2 2.1.2), using Matlab and Psychophysics toolbox v3 (Brainard, 1997; Pelli, 1997).

Participants performed 9 blocks of 40 trials each while breathing through the custom breathing circuit, with each picture thus being presented twice within a block. Each trial the participants viewed one single emotional picture for $4 \mathrm{~s}$, with a jittered inter-trial interval of 2-2.5 s. For each participant, the order of the picture presentation within each block was randomized. The manipulated independent variables were Condition (perceived RLIB, anticipated RLIB, and baseline) and Emotion (positive, neutral, and negative); see Juravle et al., 2014, for a similar methodology. So as to reinforce the current experimental condition, each of the pictures presented within the block was enclosed in a coloured rectangle (i.e., blue for perceived RLIB, red for anticipated RLIB, and green for the baseline condition, see Bublatzky, Guerra, Pastor, Schupp, \& Vila, 2013; Bublatzky \& Schupp, 2012, for a comparable paradigm).

Participants were instructed to watch the pictures within each block, while keeping the amount of eye-movements to a minimum. For the RLIB condition, the participants viewed the emotional pictures while breathing through resistive loads. The baseline condition was kept unloaded. In the anticipated RLIB condition, the participants also breathed through the unloaded system. However, they were told to expect up to three occurrences of a very severe load, which they rated in the pre-test phase as inducing a breathlessness intensity of 9 or higher on the Borg scale. For each block, we only delivered one severe load ( $8 \mathrm{~s}$ duration), this load was delivered at the beginning of a randomly chosen trial from the last third of the trials in the anticipated RLIB block. These severely loaded trials from the anticipated RLIB condition were excluded from final data analysis, such that the baseline and the anticipated RLIB had the same physical characteristics with respect to the respiratory processes, but only the expectations with regard to the experimental 


\section{ANTICIPATING AND PERCEIVING BREATHLESSNESS}

manipulation differed. The order of the experimental blocks was counterbalanced across participants. The total duration of the experiment was approximately one hour.

\section{Statistical data analysis}

For each of the dependent measures (perceptual and threat ratings and ERPs), separate repeated measures analyses of variance (ANOVAs) were carried out with the factors Condition (perceived RLIB vs. anticipated RLIB vs. baseline) and Emotion (positive vs. neutral vs. negative), and the between-factor of Group (low vs. high anxious). We performed a median split on our sample based on the ASI 3 questionnaire summary scores. Two of our participants' scores coincided with the sample median (ASI 3 summary score equal to 19), these two participants were removed from all analyses. The final sample thus consisted of 34 participants with 17 participants in each of the low and high anxious participants groups. Each experimental group was composed of 8 female participants and 9 male participants.

Mauchly's test of sphericity was used to ensure that the data did not violate the sphericity assumption. If the assumption was violated, then the Greenhouse-Geisser correction was applied to correct the degrees of freedom; corrected $p$ values are reported throughout (Picton et al., 2000). Significant main effects found in the data were followed up with one-tailed paired-samples $t$-tests. Partial $\eta^{2}$ is reported as an effect size estimate for the ANOVA results.

\section{RESULTS}

\section{Subjective ratings}

All mean ratings split by the experimental factors of Condition, Emotion, and Group are presented in Table 2. Subjective ratings main effects are depicted in Figure 2. Note that for one of the participants in the high anxious group the ratings data were over-written at the time of data 


\section{ANTICIPATING AND PERCEIVING BREATHLESSNESS}

collection, therefore, the sample sizes for the reported ratings analyses are $\mathrm{N}=17$ for the low anxious group, and $\mathrm{N}=16$ for the high anxious group.

Intensity ratings. A significant effect of Condition was observed for the breathlessness intensity ratings $\left(F(2,62)=95.67, p<.001, \eta^{2} p=.755\right)$, indicating that breathlessness intensity was rated as significantly lower during the baseline unloaded condition, as compared to both the perceived RLIB $\left(F(1,31)=205.17, p<.001, \eta^{2} p=.869\right)$ and the anticipated $\operatorname{RLIB}(F(1,31)=$ 118.77, $p<.001, \eta^{2}{ }_{p}=.793$ ), with the anticipated RLIB rated as significantly less intense relative to the perceived $\operatorname{RLIB}\left(F(1,31)=6.16, p=.019, \eta^{2}=.166\right)$. Furthermore, a main effect of Emotion was also evident in the intensity ratings $\left(F(2,62)=3.46, p=.038, \eta^{2}=.100\right)$, with breathlessness being rated significantly more intense when participants viewed negative pictures as compared to neutral pictures $\left(F(1,31)=5.53, p=.025, \eta^{2}{ }_{p}=.151\right)$. All other main effects and interactions did not reach significance on the intensity ratings data (all $p \mathrm{~s}>.113$ ).

Unpleasantness ratings. The unpleasantness ratings revealed a main effect of Condition $\left(F(2,62)=47.99, p<.001, \eta_{p}^{2}=.608\right)$, with participants rating the perceived $\operatorname{RLIB}(F(1,31)=$ 84.01, $\left.p<.001, \eta_{p}^{2}=.730\right)$ and the anticipated $\operatorname{RLIB}\left(F(1,31)=64.17, p<.001, \eta_{p}^{2}=.674\right)$ as significantly more unpleasant as compared to baseline; no difference was found between the two RLIB conditions $\left(F(1,31)=1.48, p=.234, \eta^{2} p=.045\right)$. Further, a main effect of Emotion was found $\left(F(2,62)=14.30, p<.001, \varepsilon=.644, \eta_{p}^{2}=.316\right)$, indicating that breathlessness was perceived significantly more unpleasant when participants were viewing negative pictures, as compared to both positive $\left(F(1,31)=20.10, p<.001, \eta^{2}{ }_{p}=.393\right)$, and neutral pictures $(F(1,31)=11.46, p=.002$, $\left.\eta_{p}^{2}=.270\right)$, with no significant difference in reported unpleasantness ratings between viewing neutral and positive pictures $\left(F(1,31)=2.95, p=.096, \eta_{p}^{2}=.087\right)$. No other main effects or 


\section{ANTICIPATING AND PERCEIVING BREATHLESSNESS}

interactions were significant for the unpleasantness rating data (all $p \mathrm{~s}>.490$ ).

Fear ratings. The fear rating data revealed a main effect of Condition $(F(2,62)=20.69, p$ $<.001, \eta_{p}^{2}=.400$ ), with participants indicating significantly elevated fear under conditions of both perceived $\operatorname{RLIB}\left(F(1,31)=21.83, p<.001, \eta^{2} p=.413\right)$ and anticipated $\operatorname{RLIB}(F(1,31)=34.34, p$ $\left.<.001, \eta_{p}^{2}=.526\right)$ relative to baseline, with no difference in fear ratings between the two breathlessness conditions $\left(F(1,31)=1.02, p=.321, \eta^{2} p=.032\right)$. Furthermore, a main effect of Emotion was also found $\left(F(2,62)=19.04, p<.001, \varepsilon=.788, \eta^{2}{ }_{p}=.381\right)$, indicating a significantly lowered fear for positive picture viewing as compared to both neutral $\left(F(1,31)=9.69, p=.004, \eta^{2} p\right.$ $=.238)$ and negative pictures $\left(F(1,31)=27.92, p<.001, \eta^{2}{ }_{p}=.474\right)$. The fear ratings were also significantly higher for negative relative to the neutral picture viewing $(F(1,31)=12.94, p=.001$, $\left.\eta_{p}^{2}=.295\right)$. A significant interaction between Condition, Emotion, and Group was also found $\left(F(4,124)=2.73, p=.031, \eta^{2} p=.082\right)$. Separate ANOVAs were conducted for each of the low and high anxious group with the factors Condition and Emotion. The interaction between the two factors was not significant in the case of the low anxious group $\left(F(4,60)=.59, p=.673, \eta^{2}{ }_{p}=.035\right)$. However, it reached significance for the high anxious group $\left(F(4,60)=3.46, p=.013, \eta^{2}=.187\right)$. Post-hoc tests indicated that fear ratings were significantly elevated for positive picture viewing during perceived RLIB as compared to baseline $(t(15)=3.38, p=.005, r=.39)$, for neutral picture viewing during both perceived $\operatorname{RLIB}(t(15)=5.21, p=.004, r=.50)$ and anticipated $\mathrm{RLIB}(t(15)=$ 6.23, $p<.001, r=.04)$ relative to baseline, as well as for negative pictures viewing during perceived RLIB as compared to baseline $(t(15)=5.19, p=.004, r=.48)$.

\section{ERPs}




\section{ANTICIPATING AND PERCEIVING BREATHLESSNESS}

Averages of the ERP data split according to the manipulated experimental variables are presented in Table 2. We report the ERP results split into Affective processing results (i.e., any Emotion main effects encountered for all analysed ERP deflections), Perceived RLIB and anticipated RLIB results (i.e., any Condition main effects encountered for all analysed ERP deflections), and Group effects (i.e., any Group main effect as well as interactions effects encountered for all analysed ERP deflections).

Affective processing. The Emotion main effects found in the ERP data are presented in Figure 3a. No main effects of Emotion were evident for the P1. Significant main effects of Emotion were observed for the $P 2\left(F(2,64)=3.31, p=.043, \eta^{2}=.094\right)$, the early $\operatorname{LPP}(F(2,64)=62.93, p$ $\left.<.001, \eta_{p}^{2}=.663\right)$, and the late $\operatorname{LPP}\left(F(2,64)=43.80, p<.001, \eta_{p}^{2}=.578\right)$. Planned comparisons indicated that the $P 2$ was significantly elevated for negative picture viewing, relative to the neutral ones $\left(F(1,32)=5.62, p=.024, \eta^{2}{ }_{p}=.149\right)$. The early LPP was also, as expected, significantly less positive in response to neutral picture viewing, as compared to both the positive pictures $(F(1,32)=$ 92.08, $\left.p<.001, \eta^{2}{ }^{2}=.742\right)$, and the negative pictures $\left(F(1,32)=87.24, p<.001, \eta^{2}{ }_{p}=.732\right)$, with the positive pictures also eliciting a significantly more positive early $L P P$ as compared to the negative ones $\left(F(1,32)=8.34, p=.007, \eta^{2}{ }_{p}=.205\right)$. A similar effect was also found for the late LPP time window, with a significantly less positive late LPP elicited for the neutral pictures viewing, as compared to both the positive $\left(F(1,32)=73.19, p<.001, \eta^{2}=.696\right)$, and the negative late LPPs $\left(F(1,32)=47.85, p<.001, \eta^{2}=.599\right)$; no significant difference was observed between the late LPPs for the positive and negative picture viewing $\left(F(1,32)=3.60, p=.067, \eta^{2}{ }_{p}=.101\right)$. 


\section{ANTICIPATING AND PERCEIVING BREATHLESSNESS}

Perceived RLIB and anticipated RLIB manipulations. Results indicated no main effects of Condition on the $P 1$ and the late LPP, but on the $P 2\left(F(2,64)=3.56, p=.044, \varepsilon=.868, \eta^{2} p\right.$ $=.100)$ and the early $\operatorname{LPP}\left(F(2,64)=3.98, p=.023, \eta^{2}{ }_{p}=.111\right)$. Planned comparisons indicated that the $P 2$ was significantly less positive during the perceived RLIB as compared to the baseline condition $\left(F(1,32)=7.85, p=.009, \eta_{p}^{2}=.197\right)$. Similarly, the early LPPs derived for the perceived $\operatorname{RLIB}\left(F(1,32)=7.16, p=.012, \eta^{2} p=.183\right)$ and the anticipated $\operatorname{RLIB}\left(F(1,32)=5.68, p=.023, \eta^{2} p\right.$ $=.151$ ) were significantly less positive as compared to baseline, with no significant difference found between the RLIB conditions $\left(F(1,32)=.074, p=.787, \eta^{2} p=.002\right)$. See Figure $3 \mathrm{~b}$ for a depiction of the Condition main effects encountered in the ERP data.

\section{Group effects}

P1. Group effects were evident for the $P 1$ deflection, with high anxious participants eliciting a significantly more positive $P 1$, as compared to the low anxious participants $(F(1,32)=9.11, p$ $\left.=.005, \eta^{2}{ }^{2}=.222\right)$. See Figure 4 for a depiction of the Group effect on the P1 deflection. For the P1, we also found an interaction between Group and Emotion on the ERP data $(F(2,64)=3.22, p$ $=.046, \eta_{p}^{2}=.092$ ), with the high anxious participants eliciting a significantly more positive $P 1$ in response to viewing both positive pictures $(t(32)=3.20, p=.001, r=.49)$, as well as negative pictures $(t(32)=3.41, p=.001, r=.52)$, relative to viewing neutral pictures. No group effects or interactions were found for the $P 2$ deflection.

Three-way interactions between the manipulated variables of Condition and Emotion and the between-variable Group were found for both the early $\operatorname{LPP}\left(F(4,128)=3.64, p=.008, \eta^{2} p\right.$ $=.102)$, as well as the late $L P P$ deflections $\left(F(4,128)=4.21, p=.003, \eta^{2}{ }_{p}=.116\right)$. Since the overall main effects of Condition and Emotion were reported in the sections above, here we concentrate on the resulting interesting two-way interactions between Condition and Emotion found for the 


\section{ANTICIPATING AND PERCEIVING BREATHLESSNESS}

low/high anxious groups, as well as any significant interaction existing between our betweenparticipants variable Group and either Condition or Emotion. The LPP interaction is depicted in Figure 5.

Early LPP. For the early LPP, a significant interaction between Condition and Emotion was found for the low anxious group $\left(F(4,64)=3.44, p=.013, \eta^{2} p=.177\right)$. Post hoc tests indicated that the early LPP was significantly less positive when the low anxious participants viewed positive pictures during perceived RLIB as compared to both the anticipated RLIB $(t(16)=2.29, p=.018, r$ $=.88)$ and the unloaded baseline conditions $(t(16)=3.16, p=.003, r=.89)$. Conversely, a significantly more positive early $L P P$ was evident during negative pictures viewing under perceived RLIB, as compared to anticipated RLIB $(t(16)=2.58, p=.010, r=.91)$. The high anxious participants in turn elicited a less positive early LPP during perceived RLIB negative picture viewing as compared to the unloaded baseline $(t(16)=2.55, p=.010, r=.90)$.

Late LPP . For the late LPP, on the anticipated RLIB data we found the direct group effect, that is, the late LPPs were significantly more positive in the high anxious group during neutral picture viewing, as compared to the low anxious group $(t(32)=2.28, p=.014, r=.37)$. Furthermore, we found a significant interaction between Condition and Emotion for the high anxious group $\left(F(4,64)=3.00, p=.025, \eta^{2} p=.158\right)$. Post hoc tests indicated that the late LPP was significantly less positive when participants viewed negative pictures during perceived RLIB as compared to both anticipated RLIB $(t(16)=2.62, p=.009, r=.69)$, and the unloaded baseline conditions $(t(16)=2.60, p=.009, r=.79)$. A significant interaction between Condition and Group was further found on the late LPPs during negative picture viewing only $(F(4,64)=5.18, p=.008$, $\left.\eta_{p}^{2}=.139\right)$. The low anxious participants elicited a significantly more positive late LPP during the perceived RLIB negative picture viewing, as compared to the anticipated RLIB $(t(16)=2.23, p$ $=.020, r=.70)$. 


\section{ANTICIPATING AND PERCEIVING BREATHLESSNESS}

\section{DISCUSSION}

The present study investigated the effect of anticipated and perceived breathlessness on the processing of emotional stimuli and the role of anxiety sensitivity. For this, we concentrated on ERPs elicited in response to positive, neutral, and negative affective pictures under conditions of anticipated and perceived breathlessness, as compared to an unloaded baseline.

In what regards the subjective ratings, our results highlight the expected effects, with participants rating breathlessness in both RLIB conditions as being significantly more intense and unpleasant, relative to the baseline conditions. Similarly, participants reported elevated fear during both anticipated and perceived breathlessness, as compared to baseline. These findings are in line with other studies that utilized RLIB (e.g., Alius, Pané-Farré, von Leupoldt, \& Hamm, 2013; Pappens, Vandenbossche, Van den Bergh, \& Van Diest, 2015; Stoeckel, Esser, Gamer, Büchel, et al., 2015) and suggest that our experimental manipulations of breathlessness were successful.

Across conditions, the intensity and especially the unpleasantness of breathlessness were rated as significantly elevated during negative relative to positive and neutral picture viewing, which corresponds with previous findings (von Leupoldt et al., 2008). Likewise, experienced fear significantly increased from positive to neutral to negative picture viewing. Notably, the high anxious participants exhibited elevated fear during neutral picture viewing under conditions of both perceived and anticipated breathlessness, as compared to the baseline condition. This enhanced fear aligns with previous reports in anxiety-sensitive individuals (Alius et al., 2013; Melzig et al., 2008; Paulus, 2013). Even more, our results indicate that when being exposed to a respiratory threat context, high anxious individuals demonstrate heightened fear as a sort of 'baseline behaviour', which is not encountered in low anxious individuals. 


\section{ANTICIPATING AND PERCEIVING BREATHLESSNESS}

Affective processing highlighted the expected results: That is, positive and negative picture viewing resulted in significantly more positive ERPs (e.g., P2, early and late LPPs) as compared to the ERPs elicited to the neutral pictures. As such, our results underline the increased selective and sustained attentional processing of motivationally salient stimuli as demonstrated in previous studies (Codispoti, Ferrari, \& Bradley, 2006; Hajcak, MacNamara, Foti, Ferri, \& Keil, 2013; Schupp, Junghöfer, Weike, \& Hamm, 2003; Schupp, Schmälzle, Flaisch, Weike, \& Hamm, 2013).

With respect to the respiratory threat manipulations, replicating our previous results of altered ERPs under conditions of perceived breathlessness (Juravle et al., 2014), we find that perceived breathlessness leads to less positive P2 and early LPP, as compared to the unloaded baseline condition. Results such as these suggest that breathlessness reduces the neural processing capacity for affective picture viewing, as it was previously demonstrated for painful stimulation (Wieser et al., 2012). Our previous study also indicated a trend toward a reduced LPP during breathlessness specifically in relation to positive picture viewing. We now replicate this result in the low anxious group of participants, as well as we report an additional LPP increase for negative picture viewing during RLIB. We argue in favour of this LPP response pattern related to breathlessness to likely reflect motivational priming. Motivational priming theory suggests that threatening stimuli activate the defensive system and activate negative affective processing, whereas appetitive stimuli that promote survival will activate the appetitive system and facilitate positive affective processing in turn (Bradley, Codispoti, Cuthbert, \& Lang, 2001; Lang, 1995).

Importantly, the sustained early LPP is also significantly less positive during the anticipated RLIB breathlessness. Such a result suggests that the mere anticipation of respiratory threat reduces sustained attention for parallel affective stimuli and captures neural processing capacities in a comparable manner to the real perception of breathlessness. These results are in line with previous 


\section{ANTICIPATING AND PERCEIVING BREATHLESSNESS}

studies demonstrating that anticipating breathlessness results in pronounced physiological fearrelated responses (Holtz et al., 2012; Melzig et al., 2008; Stoeckel, Esser, Gamer, Kalisch, et al., 2015). These findings thus support recent accounts that the anticipation of breathlessness might play a crucial role in respiratory and anxiety disorders (Hayen et al., 2013; Paulus, 2013).

We have previously demonstrated a significantly blunted P1 elicited under conditions of breathlessness, as opposed to an unloaded baseline (Juravle et al., 2014). Here, we bring further evidence that this effect is modulated by anxiety sensitivity levels in a particularly early time window. High anxious participants exhibit a significantly more positive P1 as compared to low anxious participants. Even more, behavioural ratings of fear are significantly elevated for the high anxious participants, as compared to the low anxious ones. These early ERP modulations as a function of anxiety sensitivity affecting the ERP are taken to reflect an early attention enhancement to affective pictures (e.g., hypervigilance), evident in a context of both perceived and anticipated respiratory threat for the high anxious individuals. This finding converges with previous studies demonstrating that anxiety-sensitivity has a marked impact on the processing of emotional stimuli (Sussman, Szekely, Hajcak, \& Mohanty, 2015) and is prominently related to respiratory threat signals such as breathlessness (Alius et al., 2013; Melzig et al., 2008).

Additionally, our results indicate a further dissociation between the two groups of participants, particularly with respect to negative picture viewing: In line with the motivational priming theory (Bradley et al., 2001; Lang, 1995), low anxious participants elicit significantly more positive early and late LPPs during perceived breathlessness as compared to baseline, whereas the same effect is reversed for the high anxious participants, who in turn show significantly blunted LPPs for the perceived breathlessness condition relative to both baseline and anticipated breathlessness conditions. Therefore, it seems that for high anxious individuals negative emotional 


\section{ANTICIPATING AND PERCEIVING BREATHLESSNESS}

material is distinctly processed in the later time window of the sustained LPP, presumably because they focus more on the bodily threatening stimulation, with the direct result of a reduced neural capacity for the picture processing. This interpretation is in line with previous observations in high anxiety sensitive individuals who showed stronger and prolonged activation of fear-related brain areas in response to respiratory threat cues (Holtz et al., 2012).

Taken together, the present results demonstrate that both the perception as well as the anticipation of breathlessness result in significantly diminished neural processing of affective picture stimuli. Furthermore, our results highlight that anxiety sensitivity impacts on the neural affective processing during breathlessness both in an early, as well as later time window. That is, whereas in low anxiety perceived breathlessness affects picture processing according to the motivational priming hypothesis, high anxious participants exhibit a significantly hypervigilant state at the beginning of the picture presentations, which turns to reduced attention capture for negative affective picture stimuli in the later time windows during the perception of breathlessness. Future studies in individuals with clinical levels of breathlessness and/or anxiety are required in order to examine the clinical relevance of these findings. These studies would benefit from including further physiological measures such as measures of the startle reflex, which could provide additional insights into fearful responses during affective picture processing under anticipated and perceived breathlessness.

\section{REFERENCES}

Alius, M. G., Pané-Farré, C. a, von Leupoldt, A., \& Hamm, A. O. (2013). Induction of dyspnea evokes increased anxiety and maladaptive breathing in individuals with high anxiety sensitivity and suffocation fear. Psychophysiology, 50(5), 488-497. 


\section{ANTICIPATING AND PERCEIVING BREATHLESSNESS}

http://doi.org/10.1111/psyp.12028

Barlow, D. (2002). Anxiety and its disorders: The nature and treatment of anxiety and panic. Guilford Press.

Borg, G. A. (1982). Psychophysical bases of perceived exertion. Medicine and Science in Sports and Exercise, 14(5), 377-381. http://doi.org/10.1249/00005768-198205000-00012

Bradley, M. M., Codispoti, M., Cuthbert, B. N., \& Lang, P. J. (2001). Emotion and motivation I: Defensive and appetitive reactions in picture processing. Emotion, 1(3), 276-298. http://doi.org/10.1037/1528-3542.1.3.276

Brainard, D. H. (1997). The psychophysics toolbox. Spatial Vision, 10, 433-436. http://doi.org/10.1163/156856897x00357

Bublatzky, F., Guerra, P. M., Pastor, M. C., Schupp, H. T., \& Vila, J. (2013). Additive Effects of Threat-of-Shock and Picture Valence on Startle Reflex Modulation. PLoS ONE, 8(1), 6-11. http://doi.org/10.1371/journal.pone.0054003

Bublatzky, F., \& Schupp, H. T. (2012). Pictures cueing threat: Brain dynamics in viewing explicitly instructed danger cues. Social Cognitive and Affective Neuroscience, 7(6), 611-622. http://doi.org/10.1093/scan/nsr032

Codispoti, M., Ferrari, V., \& Bradley, M. M. (2006). Repetitive picture processing: autonomic and cortical correlates. Brain Research, 1068(1), 213-220. http://doi.org/10.1016/j.brainres.2005.11.009

Crowley, K. E., \& Colrain, I. M. (2004). A review of the evidence for P2 being an independent component process: age, sleep and modality. Clinical Neurophysiology, 115(4), 732-744. http://doi.org/10.1016/j.clinph.2003.11.021 


\section{ANTICIPATING AND PERCEIVING BREATHLESSNESS}

Cuthbert, B., Schupp, H., Bradley, M., Birbaumer, N., \& Lang, P. (2000). Brain potentials in affective picture processing: covariation with autonomic arousal and affective report. Biological Psychology, 52(2), 95-111. http://doi.org/10.1016/s0301-0511(99)00044-7

Delorme, A., \& Makeig, S. (2004). EEGLAB: An open source toolbox for analysis of single-trial EEG dynamics including independent component analysis. Journal of Neuroscience Methods, 134(1), 9-21. http://doi.org/10.1016/j.jneumeth.2003.10.009

Domschke, K., Stevens, S., Pfleiderer, B., \& Gerlach, A. L. (2010). Interoceptive sensitivity in anxiety and anxiety disorders: an overview and integration of neurobiological findings. Clinical Psychology Review, 30(1), 1-11. http://doi.org/10.1016/j.cpr.2009.08.008

Dyspnea, A. (1999). Mechanisms, assessment, and management: a consensus statement. American Thoracic Society. American Journal of Respiratory and Critical Care Medicine, 159(1), 321340.

Hajcak, G., MacNamara, A., Foti, D., Ferri, J., \& Keil, A. (2013). The dynamic allocation of attention to emotion: simultaneous and independent evidence from the late positive potential and steady state visual evoked potentials. Biological Psychology, 92(3), 447-455. http://doi.org/10.1016/j.biopsycho.2011.11.012

Hajcak, G., MacNamara, A., \& Olvet, D. M. (2010). Event-Related Potentials, Emotion, and Emotion Regulation: An Integrative Review. Developmental Neuropsychology, 35(2), 129155. http://doi.org/10.1080/87565640903526504

Hamm, A. O., Richter, J., \& Pané-Farré, C. A. (2014). When the threat comes from inside the body: a neuroscience based learning perspective of the etiology of panic disorder. Restorative Neurology and Neuroscience, 32(1), 79-93. http://doi.org/10.3233/RNN-139011 


\section{ANTICIPATING AND PERCEIVING BREATHLESSNESS}

Harver, A., \& Mahler, D. (1998). Perception of increased resistance to breathing. Lung Biology in Health and Disease, 113, 147-193.

Hayen, A., Herigstad, M., \& Pattinson, K. T. S. (2013). Understanding dyspnea as a complex individual experience. Maturitas, 76(1), 45-50. http://doi.org/10.1016/j.maturitas.2013.06.005

Holtz, K., Pané-Farré, C. A., Wendt, J., Lotze, M., \& Hamm, A. O. (2012). Brain activation during anticipation of interoceptive threat. Neuroimage, 61(4), 857-865. http://doi.org/10.1016/j.neuroimage.2012.03.019

James, W. (1894). The physical basis of emotion. Psychological Review, 1, 516-529. http://doi.org/10.1037/h0065078

Janssens, T., Verleden, G., De Peuter, S., Van Diest, I., \& Van den Bergh, O. (2009). Inaccurate perception of asthma symptoms: a cognitive-affective framework and implications for asthma treatment. Clinical Psychology Review, 29(4), 317-327. http://doi.org/10.1016/j.cpr.2009.02.006

Juravle, G., Stoeckel, M. C., Rose, M., Gamer, M., Büchel, C., Wieser, M. J., \& von Leupoldt, A. (2014). Investigating the effect of respiratory bodily threat on the processing of emotional pictures. Respiratory Physiology \& Neurobiology, 204, 41-49. http://doi.org/10.1016/j.resp.2014.05.007

Kastner, A. K., Flohr, E. L. R., Pauli, P., \& Wieser, M. J. (2015). A Scent of Anxiety: Olfactory Context Conditioning and its Influence on Social Cues. Chemical Senses, 41(2), 143-153. http://doi.org/10.1093/chemse/bjv067

Kemper, C. J., Ziegler, M., \& Taylor, S. (2009). Überprüfung der psychometrischen Qualität der deutschen Version des Angstsensitivitätsindex-3. Diagnostica, 55(4), 223-233. 


\section{ANTICIPATING AND PERCEIVING BREATHLESSNESS}

http://doi.org/10.1026/0012-1924.55.4.223

Lang, P. J. (1995). The emotion probe. American Psychologist, 50(5), 372-385. http://doi.org/10.1037/0003-066x.50.5.372

Lang, P. J., Bradley, M. M., \& Cuthbert, B. M. (2008). International affective picture system (IAPS): Affective ratings of pictures and instruction manual. Technical Report A-8.

Livermore, N., Butler, J. E., Sharpe, L., McBain, R. A., Gandevia, S. C., \& McKenzie, D. K. (2012). Panic attacks and perception of inspiratory resistiveloads in chronic obstructive pulmonary disease. American Journal of Respiratory and Critical Care Medicine, 178(1), 7 12. http://doi.org/10.1016/j.resp.2015.05.013

Meek, P. M., Lareau, S. C., \& Hu, J. (2003). Are self-reports of breathing effort and breathing distress stable and valid measures among persons with asthma, persons with COPD, and healthy persons? Heart \& Lung, 32(5), 335-346. http://doi.org/10.1016/s0147-9563(03)001006

Melzig, C. A., Michalowski, J. M., Holtz, K., \& Hamm, A. O. (2008). Anticipation of interoceptive threat in highly anxiety sensitive persons. Behaviour Research and Therapy, 46(10), 11261134. http://doi.org/10.1016/j.brat.2008.07.002

Miller, M., Crapo, R., Hankinson, J., Brusasco, V., Burgos, F., Casaburi, R., \& Wanger, J. (2005). General considerations for lung function testing. European Respiratory Journal, 26(1), 153161. http://doi.org/10.1183/09031936.05.00034505

Nelson, B. D., Hajcak, G., \& Shankman, S. A. (2015). Event-related potentials to acoustic startle probes during the anticipation of predictable and unpredictable threat. Psychophysiology, 52(7), 887-894. http://doi.org/10.1111/psyp.12418 


\section{ANTICIPATING AND PERCEIVING BREATHLESSNESS}

Nelson, B. D., Hodges, A., Hajcak, G., \& Shankman, S. A. (2015). Anxiety sensitivity and the anticipation of predictable and unpredictable threat: Evidence from the startle response and event-related potentials. Journal of Anxiety Disorders, 33, 62-71.

http://doi.org/10.1016/j.janxdis.2015.05.003

Olofsson, J. K., Nordin, S., Sequeira, H., \& Polich, J. (2009). Affective picture processing: An integrative review of ERP findings. Biological Psychology, 77(3), 247-265. http://doi.org/10.1016/j.biopsycho.2007.11.006

Oostenveld, R., \& Praamstra, P. (2001). The five percent electrode system for high-resolution EEG and ERP measurements. Clinical Neurophysiology : Official Journal of the International Federation of Clinical Neurophysiology, 112(4), 713-719. http://doi.org/10.1016/S13882457(00)00527-7

Pappens, M., Smets, E., Vansteenwegen, D., Van Den Bergh, O., \& Van Diest, I. (2012). Learning to fear suffocation: A new paradigm for interoceptive fear conditioning. Psychophysiology, 49(6), 821-828. http://doi.org/10.1111/j.1469-8986.2012.01357.x

Pappens, M., Vandenbossche, E., Van den Bergh, O., \& Van Diest, I. (2015). Interoceptive fear learning to mild breathlessness as a laboratory model for unexpected panic attacks. Frontiers in Psychology, 6(August), 1-12. http://doi.org/10.3389/fpsyg.2015.01150

Paulus, M. P. (2013). The Breathing Conundrum-Interoceptive Sensitivity and Anxiety. Depression and Anxiety, 30(4), 315-320. http://doi.org/10.1002/da.22076

Paulus, M. P., Flagan, T., Simmons, A. N., Gillis, K., Kotturi, S., Thom, N., ... Swain, J. L. (2012). Subjecting elite athletes to inspiratory breathing load reveals behavioral and neural signatures of optimal performers in extreme environments. PLoS ONE, 7(1), e29394. 


\section{ANTICIPATING AND PERCEIVING BREATHLESSNESS}

http://doi.org/10.1371/journal.pone.0029394

Pelli, D. G. (1997). The video toolbox software for visual psychophysics: Transforming numbers into movies. Spatial Vision, 10, 437-442. http://doi.org/10.1163/156856897x00366

Picton, T. W., Bentin, S., Berg, P., Donchin, E., Hillyard, S., Johnson, R., ... Taylor, M. (2000). Guidelines for using human event-related potentials to study cognition: recording standards and publication criteria. Psychophysiology, 37(2), 127-152. http://doi.org/10.1111/14698986.3720127

Schachter, S., \& Singer, J. (1962). Cognitive, social, and physiological determinants of emotional state. Psychological Review, 69(5), 379-399. http://doi.org/10.1037/h0046234

Schupp, H., Junghöfer, M., Weike, A., \& Hamm, A. (2003). Attention and emotion: an ERP analysis of facilitated emotional stimulus processing. Neuroreport, 14(8), 1107-1110. http://doi.org/10.1097/01.wnr.0000075416.59944.49

Schupp, H., Schmälzle, R., Flaisch, T., Weike, A., \& Hamm, A. (2013). Reprint of “Affective picture processing as a function of preceding picture valence: an ERP analysis". Biological Psychology, 92(3), 520-525. http://doi.org/10.1016/j.biopsycho.2013.02.002

Seidel, E.-M., Pfabigan, D. M., Hahn, A., Sladky, R., Grahl, A., Paul, K., ... Lamm, C. (2015). Uncertainty during pain anticipation: The adaptive value of preparatory processes. Human Brain Mapping, 36(October 2014), 744-755. http://doi.org/10.1002/hbm.22661

Stoeckel, M. C., Esser, R. W., Gamer, M., Büchel, C., \& von Leupoldt, A. (2015). Brain mechanisms of short-term habituation and sensitization toward dyspnea. Frontiers in Psychology, 6(June), 1-8. http://doi.org/10.3389/fpsyg.2015.00748

Stoeckel, M. C., Esser, R. W., Gamer, M., Kalisch, R., Büchel, C., \& von Leupoldt, A. (2015). 


\section{ANTICIPATING AND PERCEIVING BREATHLESSNESS}

Amygdala response to anticipation of dyspnea is modulated by 5-HTT LPR genotype. Psychophysiology, 52(7), 973-976. http://doi.org/10.1111/psyp.12417

Sussman, T. J., Szekely, A., Hajcak, G., \& Mohanty, A. (2016). It's All in the Anticipation: How Perception of Threat Is Enhanced in Anxiety. Emotion. http://doi.org/10.1037/emo0000098

Taylor, S., \& Cox, B. J. (1998). An Expanded Anxiety Sensitivity Index. Journal of Anxiety Disorders, 12(5), 463-483. http://doi.org/10.1016/S0887-6185(98)00028-0

Taylor, S., Zvolensky, M. J., Cox, B. J., Deacon, B., Heimberg, R. G., Ledley, D. R., .. Cardenas, S. J. (2007). Robust dimensions of anxiety sensitivity: Development and initial validation of the Anxiety Sensitivity Index-3. Psychological Assessment, 19(2), 176-188. http://doi.org/10.1037/1040-3590.19.2.176

Troosters, T., Van Der Molen, T., Polkey, M., Rabinovich, R. A., Vogiatzis, I., Weisman, I., \& Kulich, K. (2013). Improving physical activity in COPD: towards a new paradigm. Respiratory Research, 14(1), 1-8. http://doi.org/10.1186/1465-9921-14-115

von Leupoldt, A., Chan, P., Esser, R., \& Davenport, P. (2013). Emotions and neural processing of respiratory sensations investigated with respiratory-related evoked potentials. Psychosomatic Medicine, 75(3), 244-252. http://doi.org/10.1097/psy.0b013e31828251cf

von Leupoldt, A., \& Janssens, T. (2016). Could targeting disease specific fear and anxiety improve COPD outcomes? Expert Review of Respiratory Medicine, 10(8), 835-837. http://doi.org/10.1080/17476348.2016.1198697

von Leupoldt, A., Mertz, C., Kegat, S., Burmester, S., \& Dahme, B. (2006). The impact of emotions on the sensory and affective dimension of perceived dyspnea. Psychophysiology, 43(4), 382386. http://doi.org/10.1111/j.1469-8986.2006.00415.x 


\section{ANTICIPATING AND PERCEIVING BREATHLESSNESS}

von Leupoldt, A., Sommer, T., Kegat, S., Klose, H., Dahme, B., \& Büchel, C. (2008). The unpleasantness of perceived dyspnea is processed in the anterior insula and amygdala. American Journal of Respiratory and Critical Care Medicine, 177(9), 1026-1032. http://doi.org/10.1164/rccm.200712-1821oc

Wieser, M. J., Gerdes, A. B. M., Greiner, R., Reicherts, P., \& Pauli, P. (2012). Tonic pain grabs attention, but leaves the processing of facial expressions intact-evidence from event-related brain potentials. Biological Psychology, 90(3), 242-248.

http://doi.org/10.1016/j.biopsycho.2012.03.019

Wieser, M. J., Pauli, P., Reicherts, P., \& Mühlberger, A. (2010). Don’t look at me in anger! Enhanced processing of angry faces in anticipation of public speaking. Psychophysiology, 47(2), 271-280. http://doi.org/10.1111/j.1469-8986.2009.00938.x

\section{ACKNOWLEDGEMENTS}

This study was supported by grants from the German Research Foundation (Deutsche Forschungsgemeinschaft, DFG) - LE 1843/9-2 (AvL), and SFB-TRR 58/B05 (MW, AvL).

\section{FOOTNOTES}

\section{$\underline{\text { Footnote } 1}$}

The following loads (in $\mathrm{kPa} / \mathrm{l} / \mathrm{s}$ ) were utilized in the study, in ascending order, with the bold value as the starting test load for all of the participants: $0.15 ; 0.31 ; \mathbf{0 . 7 6} ; 1.14 ; 1.43 ; 1.65 ; 2.07$; $2.72 ; 2.87 ; 2.99$. 


\section{ANTICIPATING AND PERCEIVING BREATHLESSNESS}

\section{$\underline{\text { Footnote } 2}$}

Averages $(\mathrm{M} \pm \mathrm{SD})$ of the normative ratings of Arousal and Valence utilized in the present study. Note that there was no significant difference with respect to neither Arousal $(F(2,38)=.217$, $\left.p=.806, \eta^{2}{ }_{p}=.011\right)$, nor Valence $\left(F(2,38)=1.01, p=.374, \eta_{p}^{2}=.050\right)$, between the three sets of pictures. Valence increased from negative to neutral to positive pictures $(F(2,38)=1314.11, p$ $\left.<.001, \eta_{p}^{2}=.986\right)$, whereas arousal was comparable between negative and positive pictures $(F(1$, 19) $\left.=.002, p=.969, \eta^{2}=.000\right)$.

\section{Arousal Valence}

\begin{tabular}{ccccccc}
\hline & Positive & Neutral & Negative & Positive & Neutral & Negative \\
\hline Set 1 & $5.9 \pm .7$ & $3.4 \pm .4$ & $6.0 \pm .6$ & $7.1 \pm .5$ & $5.2 \pm .6$ & $2.2 \pm .4$ \\
\hline Set 2 & $6.1 \pm .5$ & $3.1 \pm .4$ & $6.2 \pm .6$ & $7.0 \pm .6$ & $5.1 \pm .6$ & $2.1 \pm .3$ \\
& & & & & & \\
\hline Set 3 & $6.0 \pm .6$ & $3.1 \pm .4$ & $6.0 \pm .6$ & $6.9 \pm .5$ & $5.0 \pm .6$ & $2.2 \pm .4$ \\
\hline
\end{tabular}

$\underline{\text { Footnote } 3}$

The following IAPS pictures were utilized in the present study:

Set 1- Negative: 2683, 2900, 3030, 3120, 3170, 3191, 3230, 3350, 6212, 6213, 6510, 9300, 9419, 9428, 9500, 9560, 9600, 9800, 9900, 9922; Neutral: 2191, 2214, 2272, 2280, 2302, 2385, 2396, 2480, 2495, 2512, 2880, 2890, 5390, 5410, 5875, 7100, 7130, 7290, 7493, 7550; Positive: 2208, 2216, 2352 , 4606, 4611, 4612, 4641, 4643, 4668, 4670, 4680, 4693, 7330, 8041, 8163, 8179, $8186,8370,8380,8420$.

Set 2- Negative: 2800, 3060, 3101, 3181, 3220, 3266, 3530, 6350, 6360, 7380, 9250, 9252, 9253, 9321, 9571, 9810, 9901, 9910, 9921, 9925; Neutral: 2102, 2200, 2221, 2381, 2383, 2393, 2397, 2499, 2514, 2516, 2840, 4000, 5510, 5726, 5731, 5870, 7002, 7004, 7700, 9070; Positive: 


\section{ANTICIPATING AND PERCEIVING BREATHLESSNESS}

2209, 2345, 4599, 4607, 4623, 4645, 4651, 4652, 4660, 4664, 4669, 4694, 5621, 7289, 8161, 8190, $8191,8200,8210,8490$.

Set 3- Negative: 2095, 2688, 2730, 3100, 3180, 3261, 3500, 6260, 6560, 9040, 9050, 9340, 9400, 9410, 9420, 9435, 9520, 9530, 9570, 9903; Neutral: 2037, 2038, 2190, 2210, 2215, 2271, 2440, 2441, 2493, 2570, 2595, 2749, 2850, 2870, 5471, 5740, 5800, 7025, 7234, 7590; Positive: 4597, 4608, 4610, 4625, 4626, 4649, 4658, 4659, 4676, 4690, 4697, 5629, 7460, 7660, 8034, 8170, $8185,8206,8350,8496$. 
ANTICIPATING AND PERCEIVING BREATHLESSNESS

Table 1. Demographic data $(\mathrm{M} \pm \mathrm{SD})$.

High Anxious $(\mathbf{N}=\quad$ Low Anxious $(\mathbf{N}=\quad p$

17)

17)

\begin{tabular}{lccc}
\hline Age & $27.8 \pm 3.6$ & $25.7 \pm 3.1$ & .086 \\
\hline$F V C$ & $5.2 \pm .1$ & $5.4 \pm 1.1$ & .693 \\
\hline$F E V_{1}$ & $4.1 \pm .7$ & $4.2 \pm .8$ & .614 \\
\hline$F V C \%$ & $100.7 \pm 6$ & $103.5 \pm 11.8$ & .386 \\
\hline$F E V_{1} \%$ & $96 \pm 9$ & $98.8 \pm 14.8$ & .506 \\
\hline Load strength $(\mathrm{kPA} / L / s)$ & $1.1 \pm .1$ & $1.2 \pm .1$ & .377 \\
\hline Anxiety sensitivity $(A S I 3)$ & $11.3 \pm 4$ & $26.9 \pm 7$ & $<.001$ \\
\hline
\end{tabular}

* FVC - forced vital capacity; FEV1 - forced expiratory volume in $1 \mathrm{~s}$. 


\section{ANTICIPATING AND PERCEIVING BREATHLESSNESS}

Table 2. Mean values together with standard errors for subjective and fear ratings and ERPs

\begin{tabular}{|c|c|c|c|c|c|c|c|c|c|c|c|c|c|c|c|c|c|c|}
\hline & \multicolumn{9}{|c|}{ Low anxious } & \multicolumn{9}{|c|}{ High anxious } \\
\hline & Perceived & $\overline{R L I B}$ & & Anticipal & $d R L I B$ & & Baseline & & & Perceive & RLIB & & Anticipatc & $d R L I B$ & & Baseline & & \\
\hline & Positive & Neutral & Negative & Positive & Neutral & Negative & Positive & Neutral & Negative & Positive & Neutral & Negative & Positive & Neutral & Negative & Positive & Neutral & Negative \\
\hline Intensity & $44.9 \pm 5$ & $54.9 \pm 5$ & $52.4 \pm 5$ & $45.7 \pm 6$ & $46.8 \pm 5$ & $52.7 \pm 6$ & $9.4 \pm 4$ & $4.9 \pm 2$ & $14.1 \pm 5$ & $55.4 \pm 5$ & $54.8 \pm 5$ & $61.7 \pm 5$ & $42.4 \pm 6$ & $38.9 \pm 5$ & $43.8 \pm 6$ & $15.6 \pm 4$ & $9.6 \pm 2$ & $14.8 \pm 5$ \\
\hline Unpleasantness & $34.7 \pm 5$ & $45.1 \pm 6$ & $49.6 \pm 4$ & $33.0 \pm 6$ & $37.9 \pm 5$ & $49.8 \pm 6$ & $12.1 \pm 4$ & $9.2 \pm 3$ & $20.3 \pm 6$ & $36.7 \pm 6$ & $37.6 \pm 6$ & $55.3 \pm 4$ & $31.1 \pm 6$ & $35.1 \pm 5$ & $48.7 \pm 6$ & $11.1 \pm 4$ & $10.5 \pm 3$ & $28.8 \pm 6$ \\
\hline Fear & $8.4 \pm 3$ & $11.7 \pm 5$ & $15.9 \pm 5$ & $13.0 \pm 3$ & $11.8 \pm 5$ & $21.0 \pm 5$ & $4.2 \pm 3$ & $2.7 \pm 1$ & $9.8 \pm 4$ & $16.1 \pm 3$ & $20.9 \pm 5$ & $30.8 \pm 5$ & $11.2 \pm 3$ & $29.1 \pm 5$ & $28.3 \pm 6$ & $6.3 \pm 3$ & $4.9 \pm 2$ & $14.8 \pm 4$ \\
\hline$P I(\mu V)$ & $2 \pm .6$ & $2.2 \pm .7$ & $3.0 \pm .7$ & $2.7 \pm .7$ & $2.7 \pm .7$ & $1.8 \pm .6$ & $3.1 \pm .6$ & $2.6 \pm .6$ & $2.1 \pm .7$ & $5.3 \pm .6$ & $4.1 \pm .7$ & $5.1 \pm .6$ & $4.8 \pm .7$ & $4.1 \pm .7$ & $4.8 \pm .6$ & $5.3 \pm .6$ & $4.6 \pm .6$ & $5.4 \pm .7$ \\
\hline$P 2(\mu V)$ & $1.6 \pm .8$ & $1.5 \pm .8$ & $2.0 \pm .9$ & $2.1 \pm .9$ & $1.6 \pm .8$ & $1.5 \pm .9$ & $2.2 \pm .8$ & $2.1 \pm .8$ & $2.2 \pm .9$ & $3.8 \pm .8$ & $2.8 \pm .8$ & $3.3 \pm .9$ & $3.1 \pm .9$ & $2.9 \pm .8$ & $3.5 \pm .8$ & $3.6 \pm 9$ & $3.0 \pm .8$ & $3.9 \pm .9$ \\
\hline Early LPP $(\mu V)$ & $0.2 \pm .7$ & $-1.2 \pm .7$ & $0.6 \pm .7$ & $1.2 \pm .7$ & $-1.4 \pm .6$ & $-0.2 \pm .7$ & $1.4 \pm .7$ & $-0.9 \pm .6$ & $0.2 \pm .7$ & $1.9 \pm .7$ & $-0.6 \pm .7$ & $0.8 \pm .7$ & $1.4 \pm .7$ & $-0.7 \pm .6$ & $1.3 \pm .7$ & $1.8 \pm .7$ & $-0.3 \pm .6$ & $1.6 \pm .7$ \\
\hline Late $L P P(\mu V)$ & $0.3 \pm .4$ & $-0.9 \pm .4$ & $0.7 \pm .4$ & $0.5 \pm .4$ & $-0.6 \pm .3$ & $-0.1 \pm .4$ & $1.0 \pm .4$ & $-0.6 \pm .4$ & $0.5 \pm .5$ & $0.7 \pm .4$ & $-1.2 \pm .4$ & $-0.5 \pm .4$ & $0.3 \pm .4$ & $-1.7 \pm .3$ & $0.4 \pm .4$ & $0.4 \pm .5$ & $-1.1 \pm .4$ & $0.3 \pm .5$ \\
\hline
\end{tabular}




\section{ANTICIPATING AND PERCEIVING BREATHLESSNESS}

Figure 1. Visual depiction of the staircase decision rule, as utilized in this study.

\begin{tabular}{|c|c|c|}
\hline & $\begin{array}{c}\text { Load weaker } \\
\text { than test value }\end{array}$ & $\begin{array}{c}\text { Load stronger } \\
\text { than test value }\end{array}$ \\
\hline Rating $<=\mathbf{5}$ & Previous load +1 & Previous load \\
\hline Rating $>\mathbf{5}$ & Previous load & Previous load -1 \\
\hline
\end{tabular}


Figure 2. Main effects of Condition (upper row) and Emotion (lower row) on mean intensity ratings (a, d), mean unpleasantness ratings (b, e), and mean fear ratings (c, f). Error bars represent the standard error of the mean. Participants were subjected to a perceived resistive-load-induced (RLIB) breathlessness condition, an unloaded Baseline, and to another anticipated RLIB condition.

a
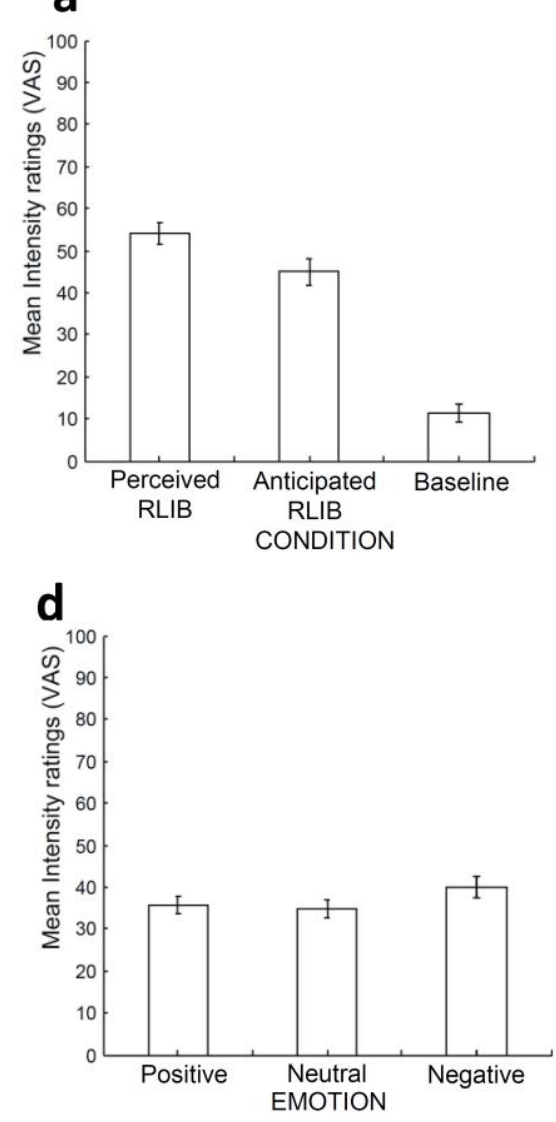

b
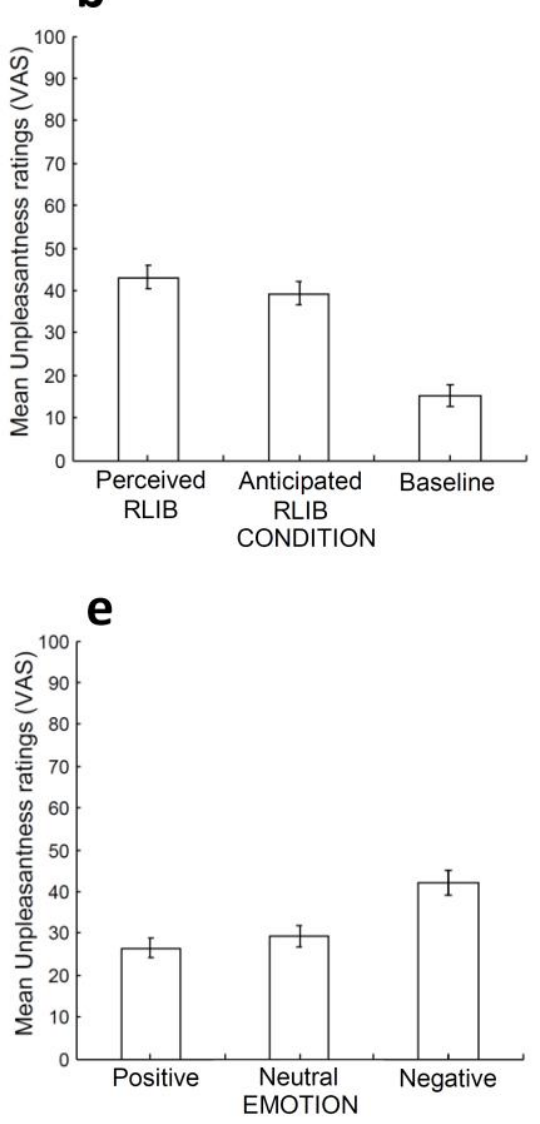

C
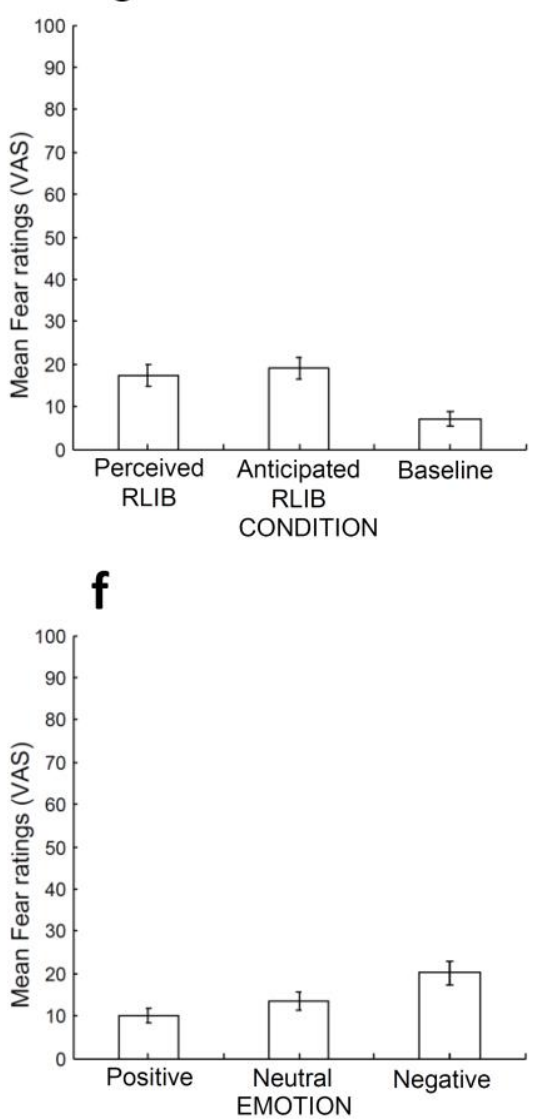


\section{ANTICIPATING AND PERCEIVING BREATHLESSNESS}

Figure 3. Main effects of Condition (a) and Emotion (b) plotted at the central electrode Pz. Topographies are calculated for the P2 time window of 230-290 ms. Participants were subjected to a perceived resistive-load-induced (RLIB) breathlessness condition, an unloaded Baseline, and to another anticipated RLIB condition.

a
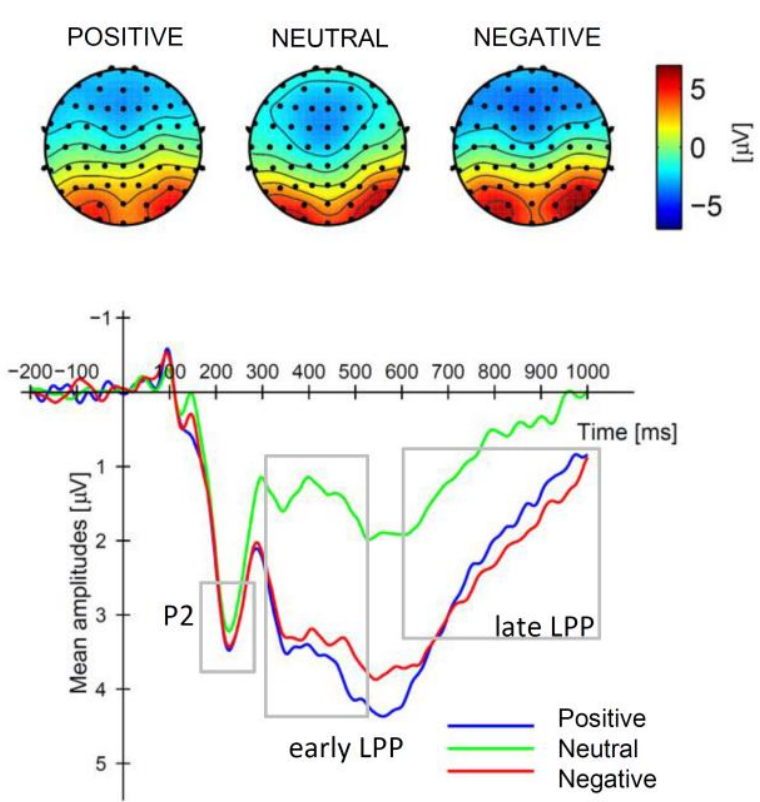

b
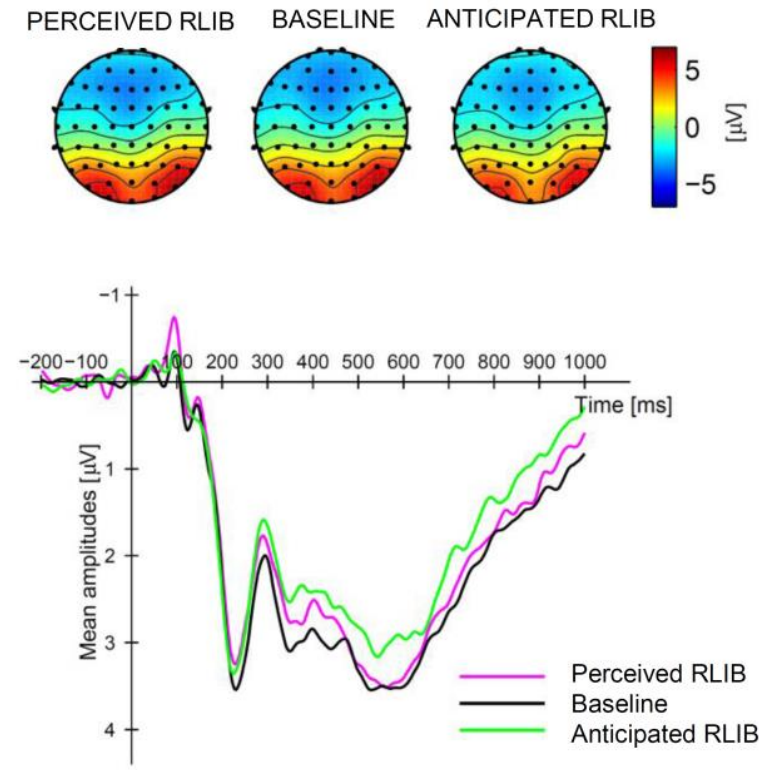


\section{ANTICIPATING AND PERCEIVING BREATHLESSNESS}

Figure 4. Group effect on P1 plotted at POz for Low anxious (LA) versus High anxious (HA) participants. Participants were subjected to a perceived resistive-load-induced (RLIB) breathlessness, an unloaded Baseline condition, and to another anticipated RLIB condition.

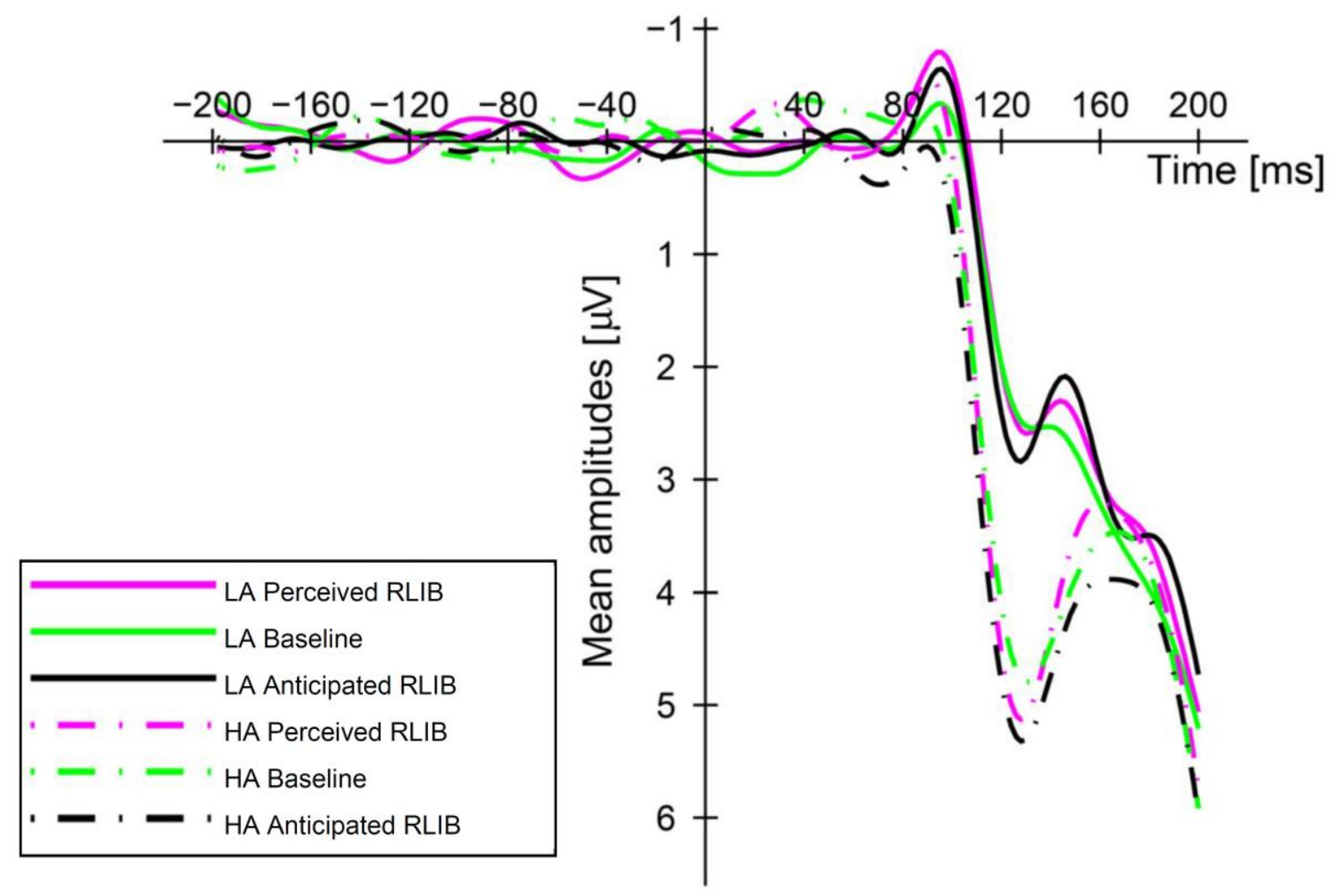




\section{ANTICIPATING AND PERCEIVING BREATHLESSNESS}

Figure 5. The late LPP interaction effect plotted at Pz for both the Low anxious (LA) versus High anxious (HA) participants. Topographies are calculated for the late LPP time window of 600-1000 ms. Participants were subjected to a perceived resistive-load-induced (RLIB) breathlessness condition, an unloaded Baseline, and to another anticipated RLIB condition.
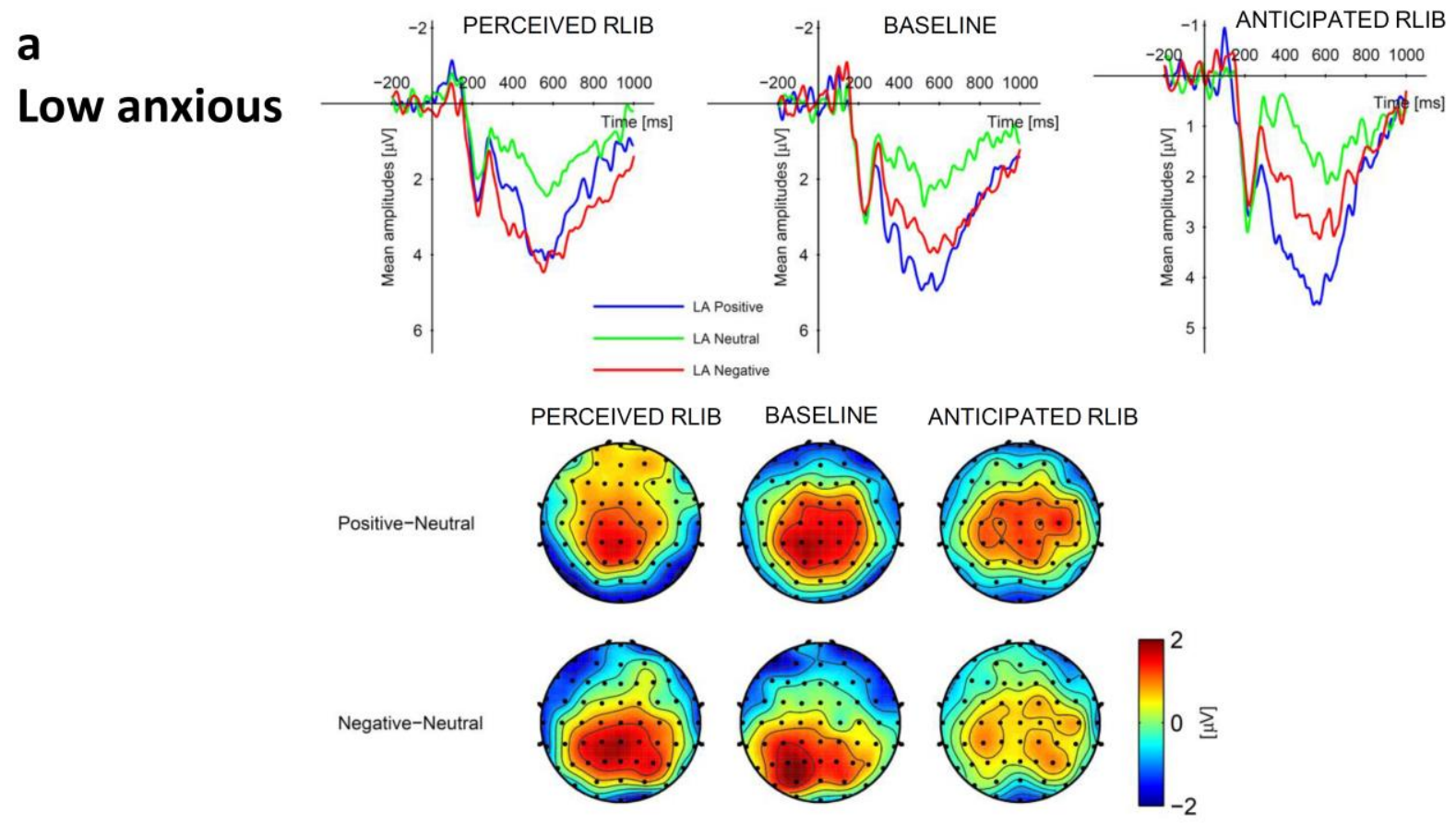

b High anxious

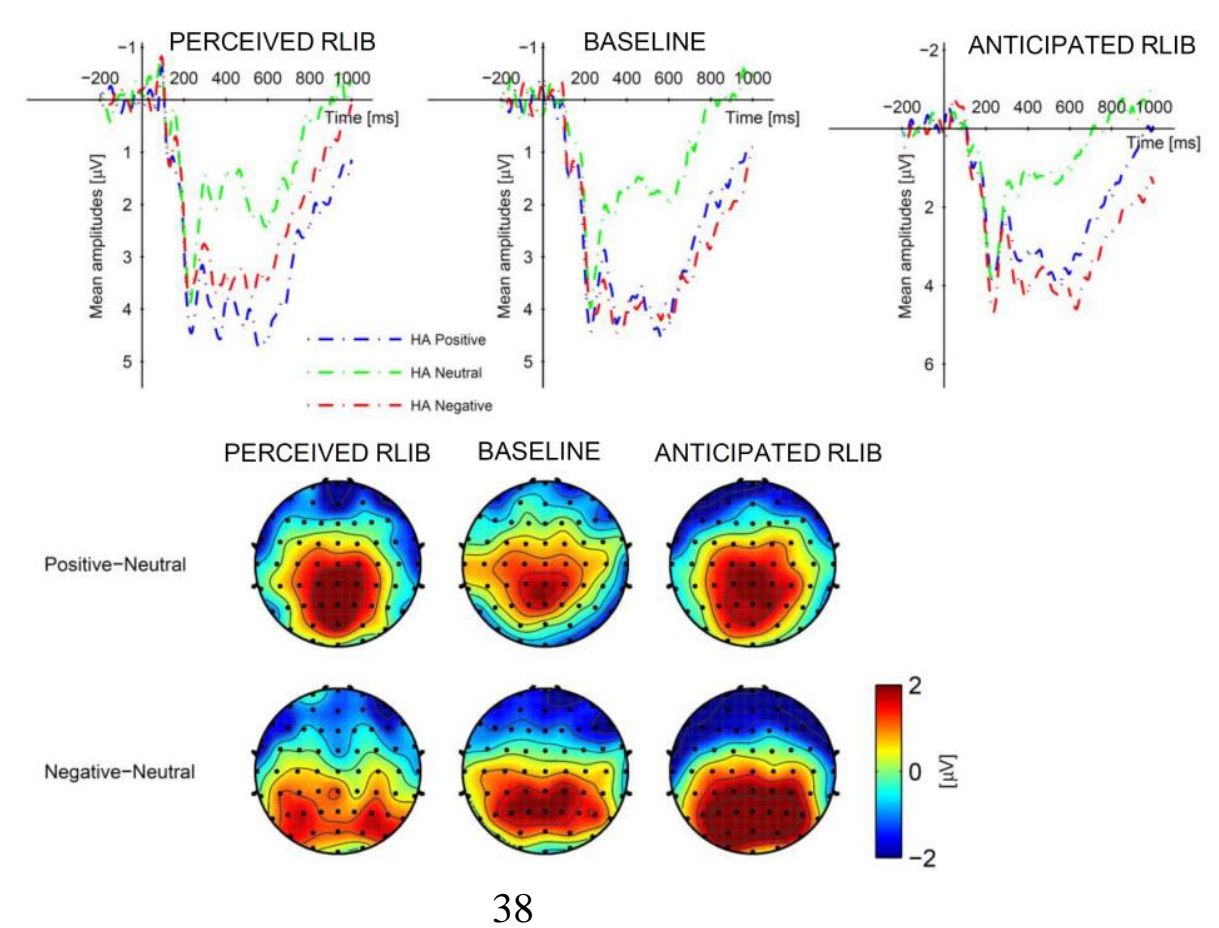

